\title{
OS REFORMADORES EMPRESARIAIS E O ENSINO MÉDIO NO BRASIL: INTERESSES E PROJETOS EM DISPUTA
}

\author{
REFORMADORES DE NEGOCIOS Y ESCUELA SECUNDARIA EN BRASIL: INTERESES \\ Y PROYECTOS EN DISPUTA
}

\section{THE BUSINESS REFORMERS AND HIGH SCHOOL IN BRAZIL: INTERESTS AND PROJECTS IN DISPUTE}

\author{
DOI: http://dx.doi.org/10.9771/gmed.v11i2.33157
}

\author{
Edson do Espírito Santo Filho ${ }^{1}$ \\ Vânia Pereira Moraes Lopes² \\ Jacob Alfredo Iora ${ }^{3}$
}

\begin{abstract}
Resumo: O presente artigo tem como finalidade discutir os interesses em disputa no processo de proposição da Reforma do Ensino Médio no Brasil. Assim, buscou-se compreender o movimento realizado por setores do empresariado ainda na década de 1990, no marco das reformas administrativas até a aprovação da Lei 13.415/2017. Realizou-se a análise bibliográfica e documental, para discutir os respectivos alinhamentos destas legislações com as propostas dos reformadores empresariais da educação. A análise aponta como o empresariado organizou-se em torno da Confederação Nacional da Indústria e Movimento Todos Pela Educação com propostas de privatização, publicização da oferta de vagas escolares e flexibilização do currículo.
\end{abstract}

Palavras-chave: ensino médio; reformadores empresariais; políticas educacionais.

Resumen: Este artículo pretende abordar la relación entre la Reforma de la Educación Secundaria en Brasil y los intereses en disputa de formación. Como esto, buscamos comprender el movimiento realizado por los sectores empresariales en la década de 1990, en el marco de las reformas neoliberales para las políticas educativas. Se realizó un análisis bibliográfico y documental para discutir las alineaciones respectivas de estas legislaciones con las propuestas de los reformadores empresariales de la educación. El análisis señala cómo se organizó la comunidad empresarial en torno a la Confederación Nacional de Industria y el Movimiento Todos por la Educación con propuestas de privatización, publicitando la oferta de plazas escolares y haciendo que el plan de estudios sea más flexible.

Palabras clave: escuela secundaria; reformadores de negocios; Políticas educativas.

Abstract: This article aims to address the relationship between the High School Reform in Brazil with dispute interests in education. Thereby, we sought to understand the movement carried out by business sectors in the 1990s, within the framework of neoliberal reforms for educational policies. A bibliographic and documentary analysis was performed to discuss the respective alignments of these legislations with the proposals of business reformers of education. The analysis points out how the business community was organized around the National Confederation of Industry and the Everyone for Education Movement with privatization proposals, publicizing the offer of school places and making the curriculum more flexible.

Keywords: high school; business reformers; educational policies.

\section{Introdução:}

A Lei no 13.415/2017 (Novo Ensino Médio), enquanto política educacional, foi aprovada no contexto de disputas de projetos dos diversos setores do empresariado, que se utilizaram da justificativa de 
que o Estado precisa se colocar à disposição do mercado para encontrar saídas para as crises estruturais do capital. Dessa forma, os investimentos em serviços sociais realizados pelo estado são considerados os causadores de crises acumulativas, e para superá-la torna-se necessário realizar reformas incluindo as políticas educacionais.

A Reforma do Ensino Médio situa-se como o resultado do tipo de intervenção dos reformadores empresariais nas políticas educacionais brasileira. Em Marx e Engels (2007), a burguesia ao reivindicar sua representação como sociedade civil e, ao mesmo tempo, classe, foi impulsionada a organizar-se nacionalmente e dar ao seu interesse uma forma geral. Neste sentido, "como o Estado é a forma na qual os indivíduos de uma classe dominante fazem valer seus interesses comuns e que sintetiza a sociedade civil inteira de uma época, segue-se que todas as instituições coletivas são mediadas pelo Estado, adquirem por meio dele uma forma política" (MARX e ENGELS, 2007, p. 76).

Em Gramsci (2007), essa relação é denominada de Estado ampliado, ou seja, a indissociabilidade entre sociedade política e sociedade civil, importante para a consolidação dos processos de hegemonia pelas classes dirigentes, que se utiliza da coerção e/ou do consenso para a garantia da direção política do Estado. No Brasil, em especial na década de 1990, os setores da burguesia passam a ter maior participação na formulação das políticas sociais, com a reforma administrativa implementada no governo Fernando Henrique Cardoso (FHC), a partir da compreensão da esfera pública não-estatal como canais de participação da sociedade civil na oferta de serviços, intensificando os processos de publicização e privatização.

Neste contexto, a alteração da Lei de Diretrizes e Bases da Educação (LDB 9.394/96), através do Decreto n 2.208/1997, possibilitou a fragmentação do ensino médio e a educação profissional, sendo esta última ofertada em grande parte pela iniciativa privada. Nos governos de Lula e Dilma, o ensino médio também sofreu suas consequências. Isso porque, mesmo com a aprovação do Decreto 5.154/2004 que retomava a discussão da integralização do ensino médio e educação profissional e com a expansão da Rede Federal de Ensino, através dos Institutos Federais, os reflexos da crise do capital vão interferir na formação e oferta de vagas nesta modalidade. Sobre a crise do capital e as orientações das reformas nos últimos governos subordinadas aos interesses econômicos internacionais, Peixoto (2017) faz a seguinte síntese:

No último século, o enfraquecimento internacional do grau de autonomia e poder dos trabalhadores, em parte, decorrente da polarização da produção da existência no capitalismo (com absoluto controle de forças produtivas e destrutivas), resulta no fortalecimento das condições para o predomínio de uma orientação liberal em todo o mundo. No Brasil, desde FHC, passando por todo o período do lulismo, sob variações de orientação liberal, um processo reformista sem reformas estruturais fortalece as condições para a propagação de um projeto de nação subordinado aos interesses econômicos internacionais. (PEIXOTO, 2017, p. 03)

Enquanto nos governos do PT transitavam reformas, disputas políticas e “ideológicas" para “solucionar o problema da educação brasileira", com o processo de impeachment ocorrido em 2016 estas reformas foram aceleradas, neste caso, a partir do documento "Uma Ponte para o Futuro", produzido pelo Partido Movimento Democrático Brasileiro (MDB). Neste documento, “os 'novos encargos' da área 
da saúde, da educação e na assistência social, que melhoraram nossa sociedade, tornaram muito difícil à administração do orçamento e isto contribuiu para a desastrosa situação em que hoje vivemos", (MDB, 2015, p. 6-7).

Na educação, destacam-se duas importantes organizações do setor privado, como agentes desta reforma: o Movimento Todos Pela Educação ${ }^{4}$ e Confederação Nacional da Indústria. Estes organismos empresariais mergulharam nos embates do congresso nacional, com o objetivo de dar a direção para os problemas da educação básica brasileira, neste caso, o ensino médio. Para tal assertiva, a parceria público privado e não responsabilização do estado com a educação, se assenta como uma solução aceitável para a insuficiência das redes públicas em ofertar vagas e no ideário da educação enquanto mercadoria.

Com o objetivo de expor os interesses em disputa para a formação da classe trabalhadora, o presente artigo discute o processo de participação dos reformadores empresariais nas propostas formuladas nos últimos governos para o ensino médio do Brasil. Em um segundo momento, buscou-se demonstrar como a aprovação da Lei 13.415/2017 abriu possibilidades para a intensificação da privatização no ensino médio no Brasil, na oferta de vagas, gestão dos sistemas de ensino e oferta de serviços educacionais.

\section{O ensino médio no contexto da reforma administrativa dos governos FHC}

A reforma administrativa implementada no governo FHC teve como pressuposto o entendimento de que o Estado deveria repassar, por meio da publicização, os denominados serviços nãoexclusivos do Estado (serviços sociais de saúde, cultura, educação) às organizações públicas não-estatais, por meio de um modelo de administração gerencial. Essa concepção, compreende a sociedade civil, enquanto esfera pública não-estatal, entre o Estado e o mercado (BRESSER PEREIRA, 1996, p. 284). Dessa forma, as organizações públicas não-estatais seriam capazes de equalizar as dificuldades do Estado garantir os serviços sociais.

Destaca-se que, a partir da década de 1990 o empresariado teve uma ampliação no tipo de participação nas políticas sociais, em especial, a educação. Esta participação foi fomentada e normatizada pelo governo FHC, através do Ministério da Administração Federal e Reforma do Estado (MARE), como saída para uma suposta crise de ineficiência do estado. Essa aproximação do empresariado nas instâncias de governo permitiu um aumento considerável de novas organizações não-governamentais (Fundações, Institutos e ONGs) na promoção de serviços sociais, a exemplo, da saúde e educação. Com isso, o governo põe em ação a Reforma administrativa do Estado Brasileiro, redefinindo o seu papel, mas também legitimando o papel da sociedade civil na oferta de serviços públicos.

Neste período, registrou-se a criação de duas importantes instituições que vão articular o empresariado brasileiro e as organizações sociais ligados a este setor: Grupo de Institutos, Fundações e Empresas (GIFE), em 1995, e o Instituto Ethos de Empresas e Responsabilidade Social (Ethos), em 1998. Dessa forma, a burguesia por meio da via jurídico-política consolidou novas formas de atuação através da normatização da Reforma Administrativa do Estado com a Emenda Constitucional no 19 de 19985. Para 
Lopes (2013), até o início dos anos 2000, a intervenção do empresariado ocorreu principalmente por meio das parcerias entre setores do empresariado e escolas públicas, através da oferta de programas e projetos de parcerias, e tinham como justificativa a disseminação de uma suposta Responsabilidade Social Empresarial (RSE) do setor produtivo.

Nessa perspectiva, as reformas educacionais da década de 1990 tinham como justificativa a necessidade de modernização do país, força de trabalho melhor qualificada e adequada aos novos processos de reestruturação produtiva. Segundo Ferreti e Silva (2017), a política educacional que orientou o ensino médio e a educação profissional no governo FHC tiveram como referência as transformações ocorridas na produção capitalista e foram materializadas por meio de documentos como a Lei 9.394/1996 (Lei de Diretrizes e Bases da Educação - LDB), e os Parâmetros Curriculares Nacionais para o Ensino Médio (PCNEM). Acrescenta-se a este ordenamento legal a promulgação da Lei 2.208/1997. Este seguiu a separação formal entre ensino médio e educação profissional, mantendo a formação por competências e habilidades, alinhadas com as orientações dos organismos multilaterais, dentre eles, o Relatório Delors (1998), no sentido de garantir um suposto pregresso técnico e uma coesão social.

\section{Os reformadores empresariais e a disputa pelo ensino médio nos governos Lula/Dilma}

A vitória do presidente Luiz Inácio Lula da Silva (P'T) parecia ser a possibilidade de inflexão desta política educacional baseada nos interesses de setores do capital. Todavia, os rumos políticos desta nova gestão apresentaram muito mais sincronias do que diacronias com a política educacional em curso, ao menos no que diz respeito à participação do empresariado como indutores de políticas educacionais.

No ensino médio, uma das primeiras ações do governo Lula foi a revogação do Decreto no 2.208/97 por um substituto, o Decreto no 5.154/04, que instituiu a possibilidade de retorno da educação profissional integrada a este nível de ensino. Mesmo com a significativa expansão de matrículas na Rede Federal de Ensino, o decreto não resolveu o problema da fragmentação do ensino médio, uma vez que as escolas de ensino médio não estavam preparadas para ofertar uma educação politécnica, assentada no trabalho como princípio educativo. Nessa situação, a educação profissional tornou-se um nicho de mercado, sendo absorvida pela iniciativa privada, impulsionada pela Lei Federal $\mathrm{n}^{\circ} 11.079 / 04{ }^{6}$, a qual regulamentava à parceria pública privada.

Segundo Martins (2008), foi neste contexto de disputas por hegemonia pela direção das políticas educacionais que em 2005 um grupo de intelectuais orgânicos, ligados aos setores do empresariado, criou o organismo Todos Pela Educação (TPE) ${ }^{7}$. Esta organização aglutina boa parte do empresariado ligado diretamente aos serviços educacionais, como também, empresas do setor produtivo e financeiro.

Neste sentido, o TPE colocou-se como orientador de políticas educacionais, diante dos problemas como a baixa qualidade da educação brasileira e seus impactos na capacidade competitiva do país, articulados com a incapacidade técnico-política de governos anteriores em resolver as questões candentes da escola pública. O Movimento apontou como princípios para a educação brasileira o cumprimento de cinco metas, a saber: toda criança e jovem de 4 a 17 anos na escola; toda criança 
plenamente alfabetizada até os 8 anos; todo aluno com aprendizado adequado a seu ano; todo jovem com o ensino médio concluído até os 19 anos; investimento em educação ampliada e bem gerido.

Dessa forma, o TPE ganhou organicidade e capilaridade por dentro do MEC, ao integrar e disputar espaços na elaboração dos principais documentos de políticas educacionais. Prova disso é que em 2006, o Movimento Todos Pela Educação realizou um evento que lançou formalmente seu projeto “Compromisso Todos Pela Educação”. No referido evento, destacou-se a presença não somente de setores do empresariado, mas também o Conselho Nacional de Secretários de Educação (CONSED) e União Nacional dos Dirigentes Municipais de Educação (UNDIME), os quais representam as esferas educacionais estaduais e municipais.

Em 2007, O Ministério da Educação (MEC) lançou o Plano de Desenvolvimento da Educação (PDE) para avaliar, investir e incentivar o desenvolvimento da educação no Brasil, tomando como referências as resoluções do documento "Compromisso Todos Pela Educação", criando o Plano de Metas que levou o mesmo nome do movimento, instituído pelo Decreto $\mathrm{n}^{\circ}$. 6.094. Em estudo sobre o Movimento Todos pela Educação, Shiroma, Garcia e Campos (2011) registram a respeito do que elas nomeiam de uma "política colaborativa", a capacidade do TPE conseguir fazer o MEC incorporar seu "compromisso", com o lançamento do PDE:

O Compromisso rapidamente ganha novas adesões, ampliando o leque de participantes com a inclusão não apenas de empresários, mas também de diversas organizações da sociedade civil, intelectuais, universidades, sindicalistas, grande mídia e, de forma especial, do próprio governo federal. Vale lembrar que adesão do MEC ao movimento se expressa na incorporação de suas metas no Plano de Desenvolvimento da Educação (PDE). Dessa forma, o movimento mantém-se, por um lado, estreitamente vinculado à esfera governamental, e por outro, assume uma posição de vigilância sobre as ações desta última, cumprindo os preceitos que anuncia para todos: responsabilização e controle social. (SHIROMA; GARCIA; CAMPOS, 2011, p. 231), \{grifos do autor\}

Em 2008, os reformadores empresariais produziram documentos que colocavam em discussão a necessidade de Reforma do Ensino Médio: “A Crise de Audiência no Ensino Médio” (Instituto Unibanco) e "Educação em Debate" (Todos Pela Educação e Instituto Unibanco). O diagnóstico realizado apontava como principais desafios: universalização do acesso; superar os altos níveis de reprovação; corrigir o abandono e evasão escolar e a distorção idade-série. No entanto, constatou-se como principais entraves para a superação destes problemas: pouco tempo de exposição dos estudantes à aprendizagem; baixo desempenho dos alunos no ensino médio noturno; deficiências na formação docente; currículo extenso, com 13 ou mais disciplinas com pouca atratividade para quem estuda; ausência dos cursos profissionais e técnicos de nível médio (BEZERRA \& ARAÚJO, 2017, p. 608).

Essa defesa apontada pelos reformadores nos documentos supracitados, e em outros que seriam produzidos posteriormente, partiu da comparação com os currículos de diversos países membros da Organização para a Cooperação e Desenvolvimento Econômico (OCDE), tomando como referência três pontos: flexibilização/diversificação curricular; formação técnica integrada ao ensino médio e; expansão do ensino em tempo integral. A intenção do empresariado agora se volta para o investimento no ensino médio, sob a justificativa de uma crise de qualidade neste nível de ensino. 
Em outra dimensão dos projetos em disputas pelo ensino médio, com ênfase na educação profissional, a CNI se colocou como importante organismo de articulação de setores produtivos no Brasil, com a criação do Senai e Sesi, na década de 1940. Na relação entre industriais e governo, a entidade apontou a necessidade de maior apoio governamental através de parcerias para a implementação da inovação tecnológica e na compra de produtos desenvolvidos pela indústria nacional. Para a educação básica, a proposta defendida pela CNI se volta para a expansão na oferta de vagas no ensino médio através da publicização (parceria público-privada).

Para responder aos desafios colocados ao capital nesse cenário contemporâneo de acirrada competitividade internacional, os empresários propõem o programa Educação para a nova indústria. Seus principais elementos são assim resumidos: expansão e diversificação da oferta de educação básica, continuada e profissional ajustada às necessidades atuais e futuras da indústria; modernização, otimização e adequação da infraestrutura física de escolas e laboratórios; flexibilização no formato e nas metodologias de atendimento às demandas educacionais da indústria; capacitação de docentes, técnicos e gestores em tecnologias e gestão dos processos educacionais (MELO, 2012, p. 36), \{grifos do autor\}.

Nos anos seguintes esse protagonismo foi consolidado através do Sistema S8, a partir do primeiro ano do governo Dilma, por meio da participação no Programa Nacional de Acesso ao Ensino Técnico e Emprego (Pronatec). Criado em 2011 com o intuito de expandir as vagas nas Redes Federal e Privada de Ensino Médio Profissional, o Programa priorizou o SENAI como principal responsável pela oferta de cursos profissionalizantes de curta duração. Freitas (2012), em estudos realizados sobre as políticas educacionais, proposto pelo Ministério da Educação (MEC), apontou a relação das políticas com os pressupostos defendidos pelos reformadores empresariais da educação, alinhadas a uma concepção de mercado de proporções internacionais, que tem como base a privatização, mediante novas formas de gestão e parcerias público-privadas, nas quais se incluem os contratos de gestão e os vouchers educacionais, no estilo Pronatec (Ensino Médio Técnico).

Para Melo e Moura (2016), já anunciavam que o principal beneficiado com o Pronatec foi o Sistema S, quando este conseguiu ser a principal parceira do Governo Dilma para a sua difusão. Isso porque, entre os anos de 2011 a 2014', um aporte de recursos de pouco mais de 200 milhões de reais para aproximadamente 1,2 bilhões para esse setor, totalizando em torno 4.5 bilhões de reais, enquanto que, somadas as Redes Federal, Estadual, Municipal e Privada não chega a 2 bilhões de reais durante o período. Para os autores, a intensificação do ensino médio como mercado de vagas e bolsas, através do Pronatec, o que recoloca um tipo de formação fragmentada e direcionada à teoria do capital humano, sendo que, para além da formação para o mercado, a produção de um atrativo mercado da formação.

Ainda para os autores, a criação do Pronatec expõe a incapacidade da escola pública em absorver o ensino médio profissional. Ao mesmo tempo, o programa promoveu um fortalecimento da intervenção do privado sobre o público e a força política do Sistema S, por meio das suas entidades de serviço social do sindicalismo patronal e supostas representantes da sociedade civil, o que demonstra outro patamar da disputa pela direção do processo formativo do ensino médio no Brasil. 
Neste sentido, a crítica que Frigotto, Ciavatta e Ramos (2014) elaboraram ao Pronatec e às transformações no ensino médio profissional no Brasil apontaram que, em suas várias reformulações, além de não promover um avanço na formação politécnica, também evidenciou que sua inserção se limitou à formação inicial e continuada, por meio de cursos de curta duração para formação de um "trabalho barato".

Este tipo de intervenção dos setores empresariais, citados anteriormente, teve um papel decisivo na elaboração do Plano Nacional de Educação (Lei 13.005/2014). O seu caráter privatista abriu caminhos para a direção a ser tomada posteriormente na Reforma do Ensino Médio. Dentre as metas e estratégias aprovadas, apresentaremos a seguir alguns destes destaques. Na Meta 6, que trata da ampliação da jornada de trabalho de tempo integral em até $50 \%$ das escolas públicas e em, no mínimo $25 \%$ das matrículas, a mesma é considerada como atividade que proporciona a ampliação da jornada de trabalho por meio de matrículas da Rede Pública, articuladas com a parceria com entidades privadas de serviço social vinculadas ao sistema sindical (Estratégia 6.5).

Já na Meta 11, apontou-se a necessidade de triplicar as matrículas da educação profissional técnica de nível médio, sendo que a oferta permite a coexistência do público com o privado. Como ações, as estratégias a serem tomadas vão desde ao aumento da oferta de educação profissional técnica de nível médio nas escolas públicas estaduais (estratégia 11.2), passando pela expansão na oferta de educação profissional à distância (estratégia 11.3). Ao Estado caberia prover a oferta de financiamento estudantil à educação profissional técnica de nível técnico, aos moldes do modelo já realizado nas matrículas do ensino superior (estratégia 11.7). Com isso, ao longo do governo Lula e Dilma, tanto o TPE quanto a CNI, se colocaram como importantes formuladores de políticas para a Reforma do Ensino Médio.

\section{O governo Temer e a Reforma do Ensino Médio}

Após o golpe realizado ao governo Dilma, os setores do empresariado vislumbraram uma possibilidade de acelerar a Reforma do Ensino Médio. Fato que pode ser identificado na produção do documento que aponta a agenda dos reformadores empresariais para o ensino médio, o Anuário Brasileiro da Educação Básica 2016, do Movimento Todos Pela Educação. De acordo com Bezerra \& Araújo (2017), os reformadores empresariais reafirmam o posicionamento levantado no ano de 2008. Neste sentido, a necessidade de mudanças no ensino médio tem como argumento imperativo tornar a escola mais atraente para os jovens, flexibilizando o currículo e instituindo a escolha de percursos escolares.

A posição dos reformadores empresariais ganhou destaque nas audiências públicas realizadas no Congresso Nacional para a discussão da MP no 746/2016. Fato que pode ser constatado na fala do Ministro Mendonça Filho, principalmente, quando aponta a necessidade de cumprimento das prerrogativas para integrar a OCDE, através da melhoria dos índices do IDEB:

O Brasil utiliza o Índice de Desenvolvimento da Educação Básica - IDEB para avaliar a aprendizagem dos alunos. Esse índice leva em consideração o fluxo escolar (taxa de aprovação, evasão e abandono), a nota da Prova Brasil para ensino fundamental e a nota do Sistema de Avaliação da Educação Básica - SAEB para o ensino médio. Na 
criação do IDEB, o Brasil definiu alcançar o índice 5,2 em 2021 com metas progressivas a cada dois anos. Essa meta está relacionada ao resultado obtido pelos 20 países mais bem colocados no mundo, que compõem a Organização para Cooperação e Desenvolvimento Econômico - OCDE (BRASIL, 2016, s/p).

Ferreti e Silva (2017), ao analisar as disputas ocorridas durante as audiências públicas realizadas no congresso nacional sobre a MP $\mathrm{n}^{\circ} 746 / 2016$, destacam que os representantes do governo federal reforçam a posição do empresariado ao defender que, um dos problemas do ensino médio estava ligado à estagnação do IDEB e ao currículo único que, nem permitia o acesso à universidade, tampouco à ampliação de matrículas no ensino técnico-profissional.

Nas audiências ficou explícito o alinhamento do posicionamento do governo com as proposições das entidades ligadas às fundações empresariais e instituições privadas de ensino. Embora os educadores profissionais, estudantes, sindicatos e universidades públicas apresentassem posicionamentos contrários às propostas da Reforma do Ensino Médio, venceu o projeto dos reformadores empresariais que, desde a década de 1990, vem ganhando capilaridade e se constituindo enquanto formuladores de políticas educacionais interno ao MEC. O Movimento Todos pela Educação e demais organizações empresariais vem avançando na implementação de sua concepção de formação, embasado em caráter produtivista da educação.

Como desdobramento desta conjuntura política, a Lei no. 13.415/2017, também conhecida como Lei da Reforma do Ensino Médio, foi aprovada após um intenso processo de resistência à Medida Provisória 746/2016, com ocupações estudantis e greves em escolas e universidades. Esses fatores ocorreram em compasso com a aprovação da Emenda Constituição 95/201610, que estabelece o congelamento de investimentos em setores sociais como saúde e educação. Para além, do suposto novo ensino médio, cabe indagar: quais os principais impactos da Lei 13415/2017 na formação da classe trabalhadora e na relação público-privado da educação brasileira? Longe de esgotar uma análise minuciosa sobre cada processo político que resultou no texto da Lei, os elementos de análise serão tomados aqui de forma pontual, tendo em vista identificar: mudanças nos currículos do ensino médio; oferta de vagas nos sistemas de ensino com a expansão do setor privado.

A justificativa da Reforma do Ensino Médio proposta pelo governo Temer se pautava no fato de que: o formato vigente com 13 componentes curriculares obrigatórios não permitia aos estudantes escolher a área de conhecimento para se especializar e; limitava a uma formação que exclui a dimensão técnico-profissional. Neste sentido, o texto aprovado da Reforma do Ensino Médio, supostamente, se coloca como maior abertura democrática de escolha por parte dos estudantes, para a definição dos seus respectivos itinerários formativos, de acordo com o que seria apontado na construção da Base Nacional Comum Curricular (BNCC). Na proposta aprovada, o currículo segue a lógica de que, após a aprendizagem de elementos gerais das diversas áreas do conhecimento, os estudantes tem a possibilidade de escolher o itinerário formativo mais atrativo e próximo da sua escolha profissional para o futuro.

Aqui, residem aspectos contraditórios para a formação dos estudantes. Por exemplo, os itinerários formativos são disponibilizados de acordo com a alocação nos sistemas de ensino e instituições escolares, e não pela escolha dos estudantes. Para Silva (2018), a BNCC e sua relação com o ensino médio 
anuncia a maior liberdade de escolha do estudante e flexibilidade nos currículos para os percursos formativos. Contudo, a autora argumenta que o seu caráter é prescritivo, com uma listagem de conteúdos e objetivos sequenciados temporalmente, caracterizada pela dimensão regulatória e restritiva, o que remete a um tipo de formação sob controle.

Quando se estabelece a relação entre o definido na Lei da Reforma do Ensino Médio com a aprovação do PNE (2014-2024) sobre a organização do currículo, destaca-se que nesta última lei, a Meta 3 (universalizar, até 2016, o atendimento escolar para toda a população de quinze a dezessete anos e elevar, até o final do período de vigência deste PNE, a taxa líquida de matrículas no ensino médio para oitenta e cinco por cento) aponta a necessidade de: maior flexibilidade e diversificação do currículo (estratégia 3.1); organização do ensino médio tomando como referência a elaboração da BNCC (estratégia 3.3); atrelado com a oferta do ensino, tendo em vista a demanda apresentada pelos estudantes (estratégia 3.11) e um maior incentivo para cursos na área de tecnologia (Estratégia 3.14).

A meta 3 do PNE remete ao terceiro aspecto problemático da relação entre a BNCC e a Reforma do Ensino Médio. A BNCC trata de quatro itinerários formativos (Linguagens e suas Tecnologias; Matemática e Suas Tecnologias; Ciências da Natureza e suas Tecnologias e Ciências Humanas e Sociais Aplicadas). Enquanto que a lei em discussão acrescenta mais um itinerário formativo, neste caso, o itinerário Formação Técnica e Profissional. Quanto ao itinerário da Formação Técnica e Profissional, a sua proposição está direcionada aos interesses da iniciativa privada, uma vez que será o setor produtivo que apontará quais cursos deverão ser fornecidos dentro deste itinerário formativo. $\mathrm{O}$ texto da lei ainda promove uma diluição dos conteúdos destes componentes curriculares nas suas respectivas áreas do conhecimento, o que restringe ainda mais as possibilidades de uma formação científica, cultural e humanística.

A Reforma do Ensino Médio estabelece a alteração progressiva da carga horária anual de 800 para 1000 horas anuais, podendo ampliar para 1400 horas. No entanto, o cumprimento desta carga horária não é atrelado necessariamente ao âmbito da instituição escolar, deixando em aberto à possibilidade das instituições privadas complementarem essa carga horária. Demandas da sociedade em geral, como universalização da educação e a construção de um currículo integral, são as justificativas utilizadas na reestruturação da política educacional para beneficiar determinado segmento da sociedade civil, os empresários educacionais.

O texto da lei remete à necessidade de um ensino médio com duas características que se diferenciam da anterior: a) uma formação aligeirada que considere a experiência profissional em curso e as certificações como complementação dos estudos; b) a possibilidade dos Sistemas de Ensino estabelecerem parcerias com o setor privado, inclusive com a oferta de vagas em instituições de Educação à Distância $(\mathrm{EaD})$. Outra alteração significativa é a possibilidade de estabelecer convênios com instituições de educação à distância como prerrogativa para o cumprimento das exigências curriculares do ensino médio e, neste caso, como possibilidade para regulamentar a carga horária dos estudantes do turno noturno.

A aprovação da Lei 13.415/2017 consolidou um ciclo percorrido pelo empresariado direcionado à privatização da educação básica pública brasileira, em especial, o ensino médio. Dentre as frações 
burguesas e seus aparelhos privados de hegemonia, a CNI e organizações empresariais ligadas ao Movimento Todos Pela Educação se apresentam como principais interlocutores para as modificações deste nível de ensino.

\section{Considerações finais}

A reforma do ensino médio, no presente artigo, compreende o desdobramento do período de duas décadas, em que teve a participação dos reformadores empresariais em diversas frentes (parlamentar, instâncias de governo e sociedade civil), através da defesa de redução do papel do estado por meio de privatização e publicização da educação pública. $\mathrm{O}$ modelo empresarial de educação institui o ensino articulado com a competitividade industrial, melhoria dos índices de avaliação (IDEB e PISA) e a necessidade da flexibilização curricular.

O tipo de intervenção organizada foi possível graças à aglutinação de suas propostas por meio de fundações, ONGs e instituições ligadas ao empresariado, com significativa ampliação de suas ações durante a reforma administrativa do governo FHC. Sendo que, nos anos 2000, se consolidou de forma mais orgânica como indutores de políticas educacionais frente às instituições governamentais.

Esta política educacional alinha-se às novas demandas do setor produtivo, pois os reformadores empresariais, ao serem protagonistas de políticas e programas de ensino, interferem no currículo, na gestão e no trabalho educativo dos espaços formativos, a escola pública. Estas ações, por sua vez, são orientadas pelos organismos internacionais e tem impactos na oferta de serviços públicos, e consequências para a formação da classe trabalhadora, a partir da redução do papel do estado.

Assim, as principais pautas destas organizações empresariais, em especial, o Movimento Todos Pela Educação e Confederação Nacional da Indústria, ganharam adesão como concepção de estado com a aprovação da Lei 13.415/2017. O caminho da parceria público-privada e da mercantilização do ensino médio se concretizou como a direção para uma suposta resolução dos problemas neste nível de ensino.

\section{Referências:}

BEZERRA, Vinicius; ARAÚJO, Carla Maluf de. A REFORMA DO ENSINO MÉDIO: Privatização da política educacional. Revista Retratos da Escola, Brasília, v. 11, n. 21, p. 603-618, jul./dez. 2017. Disponível em: <http//www.esforce.org.br>. Acesso em: 15.05.2019.

BRASIL. DECRETO N² 2.208 DE 17 DE ABRIL DE 1997. Disponível em www.planalto.gov.br/ccivil 03/decreto/D2208.htm . Acesso em: 27.05.2019.

LEI N 13.005, DE 25 DE JUNHO DE 2014, que aprova o Plano Nacional de Educação (PNE) e dá outras providências. Disponível: < http://www.planalto.gov.br/ccivil 03/ ato20112014/2014/lei/113005.htm>. Acesso: 28.05.2019.

MEDIDA PROVISÓRIA N ${ }^{\circ}$ 746, DE 22 DE SETEMBRO DE 2016. Disponível em http://www.planalto.gov.br/ccivil 03/ Ato2015-2018/2016/Mpv/mpv746.htm. Acesso: 13.07.2019.

LEI No 13.415, DE 16 DE FEVEREIRO DE 2017. Altera as Leis n_-9.394, de 20 de dezembro de 1996. Disponível em: <www.planalto.gov.br/ccivil 03/ato2015-2018/2017/lei/113415.htm>. Acesso em: 13.06.2019. 
BRESSER-PEREIRA, Luiz Carlos. Crise Econômica e Reforma do Estado no Brasil: para uma nova interpretação da América Latina. São Paulo: Editora 34, 1996.

FERRETI, Celso João; SILVA, Mônica Ribeiro da. REFORMA DO ENSINO MÉDIO NO CONTEXTO DA MEDIDA PROVISÓRIA No 746/2016: ESTADO, CURRÍCULO E DISPUTAS POR HEGEMONIA. Educ. Soc. [online]. 2017, vol.38, n.139, pp.385-404. ISSN 0101-7330. Disponível em: < http://dx.doi.org/10.1590/es0101-73302017176607>. Acesso em: 30.06.2019.

FREITAS, Luiz Carlos de. OS REFORMADORES EMPRESARIAIS DA EDUCAÇ̃̃O: DA DESMORALIZAÇÃO DO MAGISTÉRIO À DESTRUIÇÃO DO SISTEMA PÚBLICO DE EDUCAÇÃO . Educ. Soc. [online]. 2012, vol.33, n.119, pp.379-404. ISSN 0101-7330. Disponível:

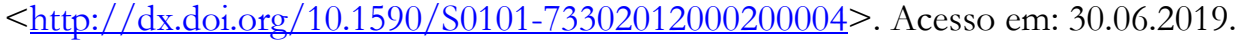

FRIGOTTOO, Gaudêncio; CIAVATTA, Maria; RAMOS, Marise. A EDUCAÇÃO DE TRABALHADORES NO BRASIL CONTEMPORÂNEO: UM DIREITO QUE NÃO SE COMPLETA. Germinal: Marxismo e Educação em Debate, Salvador, v. 6, n. 2, p. 65-76, dez. 2014. ISSN $2175-$ 5604. Disponível em: <https://portalseer.ufba.br/index.php/revistagerminal/article/view/13088>. Acesso em: 04 Out. 2019. doi:http://dx.doi.org/10.9771/gmed.v6i2.13088.

FUNDAÇÃO ULYSSES GUIMARÃES. UMA PONTE PARA O FUTURO. Disponível em: < https://www.fundacaoulysses.org.br/wp.../11/UMA-PONTE-PARA-O-FUTURO.pdf $>$. Acesso em 27.05.2019

GRAMSCI, Antônio. Cadernos do cárcere, volume 3. 3.ed. Rio de janeiro: Civilização Brasileira, 2007.

GRUPO DE INSTITUTOS, FUNDAÇÕES E EMPRESAS (GIFE). Disponível em: $<$ https://gife.org.br/>. Acesso em: 30.06.2019.

INSTITUTO ETHOS DE EMPRESAS E RESPONSABILIDADE SOCIAL (ETHOS). Disponível em: http://www3.ethos.org.br/. Acesso em: 28.06.2019.

LOPES, Christiani Bortoloto; BORTOLOTO, Claudimara Cassoli; ALMEIDA, Shiderlene Vieira de. Ensino Médio: trajetória histórica e a dualidade educacional presente nas diferentes reformas, Perspectiva, Florianópolis, v. 34, n. 2, p. 555-581, maio/ago. 2016. Disponível em:

<https://periodicos.ufsc.br/index.php/perspectiva/article/download/.../pdf>. Acesso em: 14.08.2019.

LOPES, Vania. Pereira. Moraes. A INTERVENÇÃO DO EMPRESARIADO NA EDUCAÇÃO ESCOLAR: análise das diretrizes e ações no município de Feira de Santana - Ba (2001-2008). 2013. Dissertação (Mestrado em Educação). Universidade Estadual de Feira de Santana. Feira de Santana, 2013.

MARTINS, André Silva. ESTRATÉGIAS BURGUESAS DE OBTENÇÃO DO CONSENSO NOS ANOS DE NEOLIBERALISMO DE TERCEIRA Via. In: NEVES, L.M.W. (Org.). A nova pedagogia da hegemonia: estratégias do capital para educar o consenso. São Paulo: Xamã, 2005.

A EDUCAÇÃO BÁSICA NO SÉCULO XXI: o projeto do organismo "Todos pela

Educação”. Práxis Educativa, Ponta Grossa, v.4, n.1, p.21-28, jan-jun. 2009. Disponível em:

<https://www.revistas2.uepg.br/index.php/praxiseducativa/article/view/467>. Acesso em: 20.05.2019.

MARX, Karl; ENGELS, Friedrich. A Ideologia Alemã: crítica da mais recente filosofia alemã em seus representantes Feuerbach, B. Bauer e Stirner, e do socialismo alemão em seus diferentes profetas (18451846). São Paulo: Boitempo, 2007.

MELO, Alessandro de. A educação na proposta da Confederação Nacional da Indústria nos anos 2000. Educação e Pesquisa, São Paulo, v. 38, n. 1, p. 29-45, 2012 Disponível em:

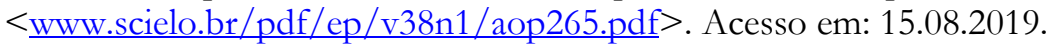

MELO, Ticiane Gonçalves Sousa de.; MOURA, Dante Henrique. PROGRAMA NACIONAL DE ACESSO AO ENSINO TÉCNICO E EMPREGO (PRONATEC): expansão e privatização da educação profissional, Holos, ano 32, vol. 6, Natal-RJ, set/2016, p. 103-119. Disponível em: < http://www2.ifrn.edu.br/ojs/index.php/HOLOS/article/view/4995>. Acesso em: 15.08.2019.

MOVIMENTO TODOS PELA EDUCAÇÃO. Disponível em: < https://www.todospelaeducacao.org.br/pag/quem-somos/>. Acesso em: 26.05.2019. 
PEIXOTO, Elza Margarida de Mendonça. CRÍTICA DA POLÍTICA EDUCACIONAL. Germinal: Marxismo e Educaşão em Debate, Salvador, v. 9, n. 1, p. 1-13, mai. 2017. ISSN 2175-5604. Disponível em: < https://portalseer.ufba.br/index.php/revistagerminal/article/view/22419>. Acesso em: 04 Out. 2019. doi:http://dx.doi.org/10.9771/gmed.v9i1.22419.

SHIROMA, Eneida.Oto.; GARCIA, Rosalba Maria Cardoso.; CAMPOS, Roselane Fátima. CONVERSÃO DAS “ALMAS” PELA LITURGIA DA PALAVRA: UMA ANÁLISE DO DISCURSO DO MOVIMENTO TODOS PELA EDUCAÇÃO, p. 222-248. In: BALL, S. J.; MAINARDES, J. (orgs). Políticas educacionais: questões e dilemas. São Paulo: Cortez, 2011.

SILVA, Monica Ribeiro da. A BNCC DA REFORMA DO ENSINO MÉDIO: O RESGATE DE UM EMPOEIRADO DISCURSO. Educ. rev. [online]. 2018, vol.34, e214130. Epub 22-Out-2018. ISSN 01024698. Disponível em: < http://dx.doi.org/10.1590/0102-4698214130>. Acesso em: 20.06.2019.

\section{Notas:}

1 Universidade Estadual de Feira de Santana, PPGE - FACED - Universidade Federal da Bahia.Mestre em Educação pela Universidade Federal da Bahia. Professor auxiliar a da Universidade Estadual de Feira de Santana e Doutorando no Programa de Pós-Graduação em Educação pela Universidade Federal da Bahia. Tem experiência na área de Educação Física, com ênfase nos seguintes temas: políticas públicas, lazer, estado e educação, currículo, escola. ORCID: https://orcid.org/0000-0003-4178$\underline{8247}$ Email: espiritosanto.edson@gmail.com

2 PPGE - FACED - Universidade Federal da Bahia. Mestre pela universidade Estadual de Feira de Santana. Pesquisadora, com foco nas políticas Educacionais e valorização da carreira docente. ORCID: https://orcid.org/0000-0002-4402-5061 Emil: vanlopsi@gmail.com

3 PPGE FACED UFBA. ORCID: https://orcid.org/0000-0002-3431-8995 Email: jacobiora07@gmail.com

4 O Todos Pela Educação é uma organização da sociedade civil, sem fins lucrativos, plural e suprapartidária. Ver mais em: $<$ https://www.todospelaeducacao.org.br/pag/quem-somos/>.

${ }_{5}$ Disponível em: <http://www.planalto.gov.br/ccivil_03/constituicao/emendas/emc/emc19.htm>.

${ }^{6}$ Disponível em: <http://www.planalto.gov.br/ccivil_03/_ato2004-2006/2004/lei/111079.htm>.

7 Empresas e organizações sociais que constituem o TPE: DPaschoal, Fundação Bradesco, Fundação Itaú Social, Fundação Telefônica, Gerdau, Instituto Unibanco, Itaú BBA, Suzano, Fundação Lemann, Instituto Península, Instituto Natura, Gol, Instituto Votorantim, Grupo ABC, Rede Globo, entre outras entidades. Ver mais em: $<$ https://www.todospelaeducacao.org.br/pag/quem-somos/>.

8 Integram o Sistema S os seguintes serviços sociais vinculados ao sindicalismo patronal: Serviço Nacional de Aprendizagem Rural - SENAR; Serviço Nacional de Aprendizagem Comercial - SENAC; Serviço Social do Comércio - SESC; Serviço Nacional de Aprendizagem do Cooperativismo - SESCOOP; Serviço Nacional de Aprendizagem Industrial - SENAI; Serviço Social da Indústria - SESI; Serviço Social do Transporte - SEST; Serviço Social de Aprendizagem do Transporte - SENAT; Serviço Brasileiro de Apoio às Micro e Pequenas Empresas - SEBRAE.

${ }^{9}$ Dados apresentados pelo FNDE e integra o Relatório de Auditoria Anual de Contas/2013 realizado pela CGU na Secretaria de Educação Profissional e Tecnológica. Brasília, 2014.

10 Trata-se da Emenda Constitucional que institui o novo regime fiscal para o orçamento da União e Seguridade Social. Durante o ano de 2016, enquanto o referido texto tramitava no Congresso Nacional, ela foi alvo de mobilizações e greve geral de diversas categorias profissionais. No período de sua tramitação esta era denominada de "PEC da Morte", uma vez que seu conteúdo aponta para a necessidade de redução de gastos em áreas sociais como saúde, educação, habitação e eguridade social. 